\title{
A review of the family Sphaeronectidae (Class Hydrozoa, Order Siphonophora), with the description of three new species
}

\author{
P.R.PUGH \\ National Oceanography Centre, Southampton, SO14 3ZH, UK. E-mail: prp@noc.soton.ac.uk
}

\section{Table of contents}

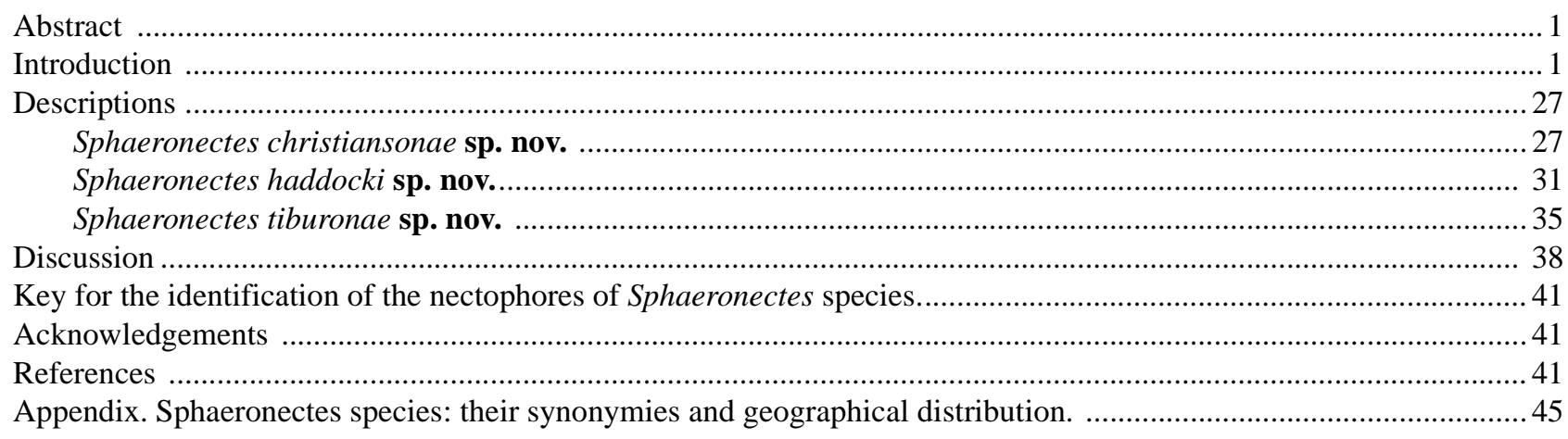

\begin{abstract}
The last reviewer of the family Sphaeronectidae (Siphonophora, Calycophorae) (Carré, 1968c) considered that it consisted of a single genus, Sphaeronectes, containing five species; three of which had been recently described by himself. For the other two species there had been much nomenclatural confusion in the past, as is herein reviewed. It is considered that for one of these species the name Sphaeronectes koellikeri Huxley (1859) has priority over the name currently in usage, that is $S$. gracilis (Claus, 1873; 1874). In addition the status of $S$. brevitruncata (Chun, 1888) is reconsidered and the species considered valid, with $S$. japonica (Stepanjants, 1967) being considered as a likely junior synonym of it. Three new Sphaeronectes species, S. christiansonae sp. nov., S. haddocki sp. nov. and S. tiburonae sp. nov., are described, and the systematic position of the genus reconsidered in the light of preliminary molecular phylogenetic data.
\end{abstract}

Key words: Siphonophora, Calycophorae, Sphaeronectes, Systematics, Phylogeny

\section{Introduction}

History of the family Sphaeronectidae

Presently the Sphaeronectidae is considered to be a small family of calycophoran siphonophores that are unique in that they retain into their adult, polygastric stage their larval nectophore and no further, definitive nectophores are developed. Thus, as for instance Totton (1965) had suggested, they can be considered neotenous. Totton (ibid. p. 201) also pointed out that "It was this beautiful and remarkable little 'monophyid' in which the stem was supposed to arise from the exumbral pole of the nectosac that gave rise to the medusoid theory of siphonophore evolution". Although in the $19^{\text {th }}$ Century sphaeronectid species had been described within two genera, Sphaeronectes and Monophyes, most, but not all, more recent reviewers have considered 